\title{
Microstructure and Residual Stress Evolution of Laser Powder Bed Fused Inconel 718 under Heat Treatments
}

\author{
Giulio Marchese, Eleonora Atzeni, Alessandro Salmi, and Sara Biamino
}

Submitted: 14 July 2020 / Revised: 13 October 2020 / Accepted: 7 November 2020 / Published online: 2 December 2020

\begin{abstract}
The current work aimed to study the influence of various heat treatments on the microstructure, hardness, and residual stresses of Inconel $\mathbf{7 1 8}$ processed by laser powder bed fusion process. The reduction in residual stresses is crucial to avoid the deformation of the component during its removal from the building platform. Among the different heat treatments, $800{ }^{\circ} \mathrm{C}$ kept almost unaltered the original microstructure, reducing the residual stresses. Heat treatments at 900,980 , and $1065^{\circ} \mathrm{C}$ gradually triggered the melt pool and dendritic structures dissolution, drastically reducing the residual stresses. Heat treatments at 900 and $980^{\circ} \mathrm{C}$ involved the formation of $\delta$ phases, whereas $1065^{\circ} \mathrm{C}$ generated carbides. These heat treatments were also performed on components with narrow internal channels revealing that heat treatments up to $900{ }^{\circ} \mathrm{C}$ did not trigger sintering mechanisms allowing to remove the powder from the inner channels.
\end{abstract}

Keywords additive manufacturing, hardness, laser powder bed fusion, microstructure, phase state, residual stress, superalloys

\section{Introduction}

Inconel 718 (IN 718) is a Ni-based superalloy characterized by high mechanical stability up to around $650{ }^{\circ} \mathrm{C}$, including elevated oxidation resistance and good fatigue life. This alloy is one of the most considered materials for aeronautics industries, such as parts of aircraft turbine engines and land-based gas turbine engines (Ref 1-7).

Nowadays, near-net-shape complex components made of IN 718 can be fabricated employing additive manufacturing (AM) processes. Among these processes, laser powder bed fusion (LPBF) enables the production of components starting from powder melted by a laser beam layer by layer, based on a 3D CAD model (Ref 8-10). The high weldability of this alloy allows the fabrication of L-PBF IN 718 components with extremely high densification levels (close to 100\%) (Ref 1114).

However, the material is subjected to extremely high cooling rates (around $10^{5}-10^{6}{ }^{\circ} \mathrm{C} / \mathrm{s}$ ) during the melting and solidification, generating extremely fine microstructures composed of dendritic/cellular structures with nanometric Laves phases, and micrometric segregations chiefly located into the interdendritic areas. Moreover, high cooling rates lead to the formation of high residual stresses within the material (Ref 11, 15-17). These high residual stresses can lead to distortion of the component as well as to reduce its fatigue life (Ref 18). It is

Giulio Marchese and Sara Biamino, Department of Applied Science and Technology, Politecnico di Torino, Corso Duca degli Abruzzi 24, 10129 Turin, Italy; and Eleonora Atzeni and Alessandro Salmi, Department of Management and Production Engineering, Politecnico di Torino, Corso Duca degli Abruzzi 24, 10129 Turin, Italy. Contact e-mail: giulio.marchese@polito.it.

therefore essential to perform subsequent heat treatments in order to mitigate the residual stresses, investigating the microstructure and mechanical properties of the post-heattreated material (Ref 17, 19, 20).

The primary studies on L-PBF IN 718 alloy have been investigated the effect of heat treatments (solution annealing and double-aging treatments) in order to homogenize the microstructure and reach adequate mechanical performance.

For instance, Tucho et al. (Ref 21) studied the effect of solution annealing at high temperatures $\left(1100\right.$ and $\left.1250{ }^{\circ} \mathrm{C}\right)$ for different times, showing the homogenization of the microstructure associated with its hardness evolution. Also, Calandri et al. (Ref 15) reported the crucial role of the chemical homogenization, investigating the phases concentration, grain structures, and hardness of L-PBF IN 718 underwent to different solution annealing from 980 to $1200{ }^{\circ} \mathrm{C}$. Zhang et al. (Ref 22) focused their attention on the effect of standard heat treatments on the phases formation and hardness compared to the traditional cast version. Cao et al. (Ref 23) examined the evolution of the phases such as $\gamma^{\prime}\left(\mathrm{Ni}_{3}(\mathrm{Al}, \mathrm{Ti})\right.$-face-centered cubic), $\gamma^{\prime \prime}$ $\left(\mathrm{Ni}_{3} \mathrm{Nb}\right.$ - body-centered tetragonal) and $\delta\left(\mathrm{Ni}_{3} \mathrm{Nb}\right.$ - orthorhombic) phases under standard heat treatments. Chlebus et al. (Ref 24) reported that double-aged L-PBF IN 718 material exhibits higher tensile properties than double-aged wrought IN 718 alloy.

Another aspect of L-PBF process is that it inherently induces residual stresses into the material that can be determined by means of different techniques (Ref 18, 25-32). Regarding IN 718, some authors revealed an estimation based on the deformation of the specimens (Ref 28), microhardness test (Ref 29), XRD analysis (Ref 30), neutral diffraction method (Ref 31), as well as hole drilling test (Ref 32).

Yi et al. (Ref 28) reported the variations of residual stresses through the degree of sample deformations produced with different process parameters. They revealed that reducing the scanning speed or increasing the laser power involves more energy to the powder, thus provoking increment of residual stresses. Nadammal et al. (Ref 31) revealed the effect of parameters on the residual stresses assessed using the neutral diffraction method. Lu et al. (Ref 29) evaluated the influence of different island scanning strategies on the residual stresses by 
means of microhardness test, indicating an adequate reduction for the size of $5 \times 5 \mathrm{~mm}^{2}$. Ahmad et al. (Ref 33) used the contour method (within the techniques based on the deformation of the sample) coupled with numerical simulation to determine the residual stresses generated within L-PBF IN 718. They assessed high tensile stresses (maximum values around $840 \mathrm{MPa}$ ) close to the surface and compressive stresses (maximum values around $460 \mathrm{MPa}$ ) in the middle of the specimens. Deng et al. (Ref 30) found high residual stresses for the as-built state (magnitude around $800-750 \mathrm{MPa}$ ), which are relieved after performing heat treatment at $1080{ }^{\circ} \mathrm{C}$ followed by double-aging treatments by means of XRD analysis. Finally, Barros et al. (Ref 32) studied the effect of residual stresses for L-PBF IN 718 subjected to standard solution annealing at $1065{ }^{\circ} \mathrm{C}$ as well as solution annealing followed by doubleaging treatments $\left(720^{\circ} \mathrm{C} 8 \mathrm{~h}+620^{\circ} \mathrm{C} 8 \mathrm{~h}\right)$ using hole drilling test, correlating the resulting values with the microstructure evolution. In this study, subsequent heat treatments (solution annealing and aging treatments) provoked a consistent reduction of residual stresses.

Nevertheless, according to the authors' knowledge, there are no studies correlating the microstructure with residual stresses evolution under different temperatures, also applying temperatures considered as possible stress relieving tailored for the LPBF material.

In the current work, a systematic study was performed in order to understand which temperature starts to be useful as stress relieving and which temperature starts to affect the microstructure of the material. Different heat treatments at 450 , 600,800 , and $900{ }^{\circ} \mathrm{C}$ were compared to the as-built, and traditional solution annealed conditions at $980{ }^{\circ} \mathrm{C}$ (AMS 5662) and $1065^{\circ} \mathrm{C}$ (AMS 5664) states, applying the same heating time $(1 \mathrm{~h})$. This study could drive to design specific heat treatments tailored for L-PBF IN 718 alloy to mitigate or eliminate the residual stresses.

\section{Materials and Methods}

\subsection{Materials and Heat Treatments}

The gas-atomized IN 718 powder supplied by EOS GmbH was used. The chemical composition is the following (in weight percent): Fe Balance, Ni 50-55\%, Cr 17-21\%, Nb 4.75-5.5\%, Mo 2.8-3.3\%, Co < 1\%, Ti 0.65-1.15\%, Al 0.2-0.8\%, Si and $\mathrm{Mn}<0.35 \%, \quad \mathrm{Cu}<0.3 \%, \quad \mathrm{P}+\mathrm{S}<0.015 \% \quad$ and $\mathrm{B}<0.006 \%$ in agreement with the UNS N07718. The gas atomized powder was characterized by particles with a cumulative frequency of $\mathrm{d}_{50}$ of around $25 \mu \mathrm{m}$ and $\mathrm{d}_{90}$ of $45 \mu \mathrm{m}$. The particle size was determined using processing images of the particles obtained by means of a scanning electron microscope (SEM). The particle presents quite spherical shapes, also exhibiting satellites and some irregular particles, as shown in Fig. 1.

Cubic samples with dimensions $10 \times 10 \times 10 \mathrm{~mm}^{3}$ were fabricated by means of an EOS M270 Dual mode version with a laser spot size of $0.1 \mathrm{~mm}$. The employed process parameters were: laser power of $195 \mathrm{~W}$, hatching distance of $0.09 \mathrm{~mm}$, scanning speed of $1200 \mathrm{~mm} / \mathrm{s}$, and layer thickness of $0.02 \mathrm{~mm}$, applying a laser scanning rotation of $67^{\circ}$ (Ref 15). The employed scanning strategy has been explained in a previous publication of some of the authors (Ref 32).

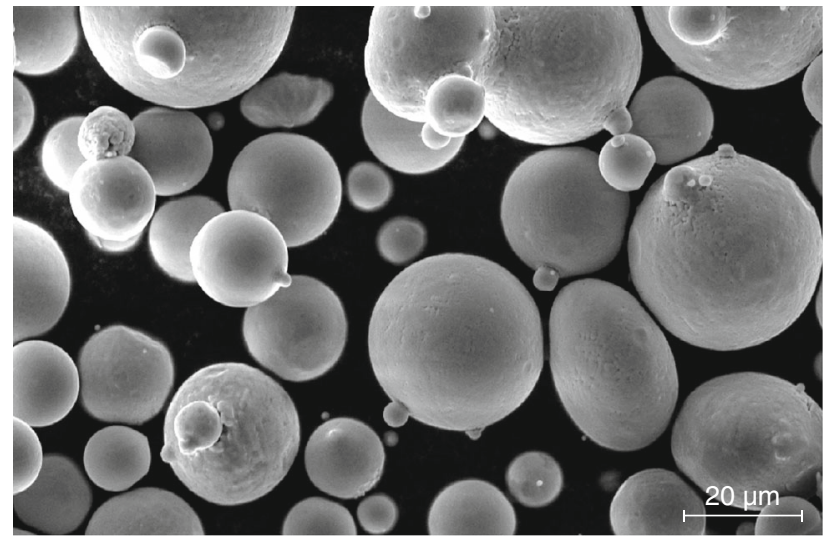

Fig. 1 SEM image of the morphology of the particles

In order to examine the residual stresses mitigation under heat treatments, different temperatures were selected. Heat treatments at $450,600,800$, and $900{ }^{\circ} \mathrm{C}$, together with standard solution annealing temperatures at $980^{\circ} \mathrm{C}$ (AMS 5662) and $1065^{\circ} \mathrm{C}$ (AMS 5664) were performed. For all these heat treatments, the heating time was kept constant to $1 \mathrm{~h}$, followed by air cooling. The heat treatments were performed in a muffle furnace in air.

\subsection{Microstructure Investigations}

The cubic samples were cut along the z-axis (building direction), ground with $\mathrm{SiC}$ paper, and polished down to $1 \mu \mathrm{m}$ using diamond suspensions. Finally, the samples were etched with Kallings' No.2 solution. A light optical microscope (LOM - Leica DMI $5000 \mathrm{M}$ ) and scanning electron microscope (SEM - Phenom XL) equipped with an energy-dispersive spectroscopy (EDS) detector was employed to study the microstructure. The lattice parameter of the austenitic matrix $(\gamma)$ was evaluated by $\mathrm{x}$-ray diffraction (XRD, PANalytical) with $\mathrm{Cu} \mathrm{K}_{\&}$ radiation at $40 \mathrm{kV}$ and $40 \mathrm{~mA}$ in a Bragg-Brentano configuration operating with a step size 0.013 and $25 \mathrm{~s}$ per step.

The Brinell hardness of the sample was determined using an EMCO TEST M4U test machine with a load of $62.5 \mathrm{~kg}_{\mathrm{f}}$ for $15 \mathrm{~s}$ (HBW2.5/62.5) following the ASTM E10 standard. The final hardness value was assessed by performing five indentations on two samples for each condition.

\subsection{Residual Stresses Measurements}

The hole-drilling method was used to evaluate the in-depth residual stresses. Thus, onto the top and lateral side of each specimen, K-RY61-1.5/120R (HBM Italia s.r.1., Italy) Type B3element rosettes were installed. Each rosette consists of a series of 3 strain gages radially arranged to the point where the hole will be produced. A RESTAN-MTS3000 (SINT Technology s.r.1, Italy) hole drilling system, equipped with a $1.8 \mathrm{~mm}$ diameter inverted-cone end mill, was then used to generate the hole in 20 steps of $0.05 \mathrm{~mm}$, and corresponding surface deformations were acquired. The EVAL 7 software (SINT Technology s.r.l, Italy) allowed to compute the residual stress profile from the acquired surface deformations, following the back calculation method for the non-uniform residual stress field described in the ASTM E837-13a standard. 


\section{Results and Discussions}

\subsection{Microstructure Evolution}

Figure 2 shows the LOM and SEM images of the as-built and heat-treated samples at 450 and $600{ }^{\circ} \mathrm{C}$ for $1 \mathrm{~h}$, cut along the building direction (z-axis). The as-built state revealed the melt pool contours generated by the laser beam and columnar grains crossing several melt pools. Samples under thermal exposures at 450 and $600{ }^{\circ} \mathrm{C}$ displayed the same microstructure features as the as-built conditions. More in detail, the as-built state revealed columnar grains mainly with a length from 30 to $200 \mu \mathrm{m}$ and a width from 10 to $50 \mu \mathrm{m}$, showing dimensions compatible with the literature (Ref 19, 22, 28). The grain size resulted in being no altered by applying heat treatments at 450 and $600{ }^{\circ} \mathrm{C}$ for $1 \mathrm{~h}$. For these conditions, the SEM micrographs exhibited fine architectures of dendritic structures. This indicates that similar temperatures did not promote either melt pool disappearing or grains modifications or any significative phase changes.

Regarding the grain sizes, higher thermal exposures did not seem to involve drastic modification on the maximum grain dimensions due to the formation of phases hindering the grain growth. Moreover, all the microstructures exhibited the presence of columnar grains, indicating no remarkable recrystallization, as displayed in the LOM images of Fig. 3. This is in line with the literature on LPBF IN 718 alloy since the recrystallization primarily occurs over $1100{ }^{\circ} \mathrm{C}(\operatorname{Ref} 15,24)$.
Higher temperatures, on the other hand, produced detectable microstructural alterations on the melt pools, dendritic structures, and phases, as visible in the SEM micrographs of the specimens heat-treated at $800,900,980$, and $1065^{\circ} \mathrm{C}$ for $1 \mathrm{~h}$ in Fig. 3.

Heat treatment at $800{ }^{\circ} \mathrm{C}$ promoted the formation of precipitates along the grain boundaries, without eliminating the melt pools or affecting the columnar grains. Samples heattreated at $900{ }^{\circ} \mathrm{C}$ still revealed precipitates along the columnar grain boundaries while the melt pools were almost completely eliminated, indicating that for this thermal exposure, dissolution mechanisms occur. Increasing the temperature at $980{ }^{\circ} \mathrm{C}$, the microstructure still exhibited intergranular precipitates along the columnar grains while the melt pools were completely dissolved. Differently, the samples heat-treated at $1065{ }^{\circ} \mathrm{C}$ for $1 \mathrm{~h}$ revealed a very low concentration of phases along the grain boundaries.

The morphology and EDS analyses (Fig. 4a-d) associated with the time-temperature-transformation (TTT) diagram of the alloy can help to identify the formed phases under the various thermal exposures. Phases enriched in $\mathrm{Nb}$ coupled to depletion of $\mathrm{Ni}$ can suggest the formation of the carbides, while enrichment in $\mathrm{Nb}$ and $\mathrm{Ni}$ can indicate the formation of $\delta$ phases $\left(\mathrm{Ni}_{3} \mathrm{Nb}\right)$. Moreover, considering that the austenitic matrix is already rich in $\mathrm{Ni}$, for small $\delta$ phases, the EDS analysis can also detect no $\mathrm{Ni}$ enrichment.

Heat treatment at $800{ }^{\circ} \mathrm{C}$ produced the formation of very fine carbides slightly enriched in $\mathrm{Nb}$ and depleted of $\mathrm{Ni}$ and $\mathrm{Cr}$

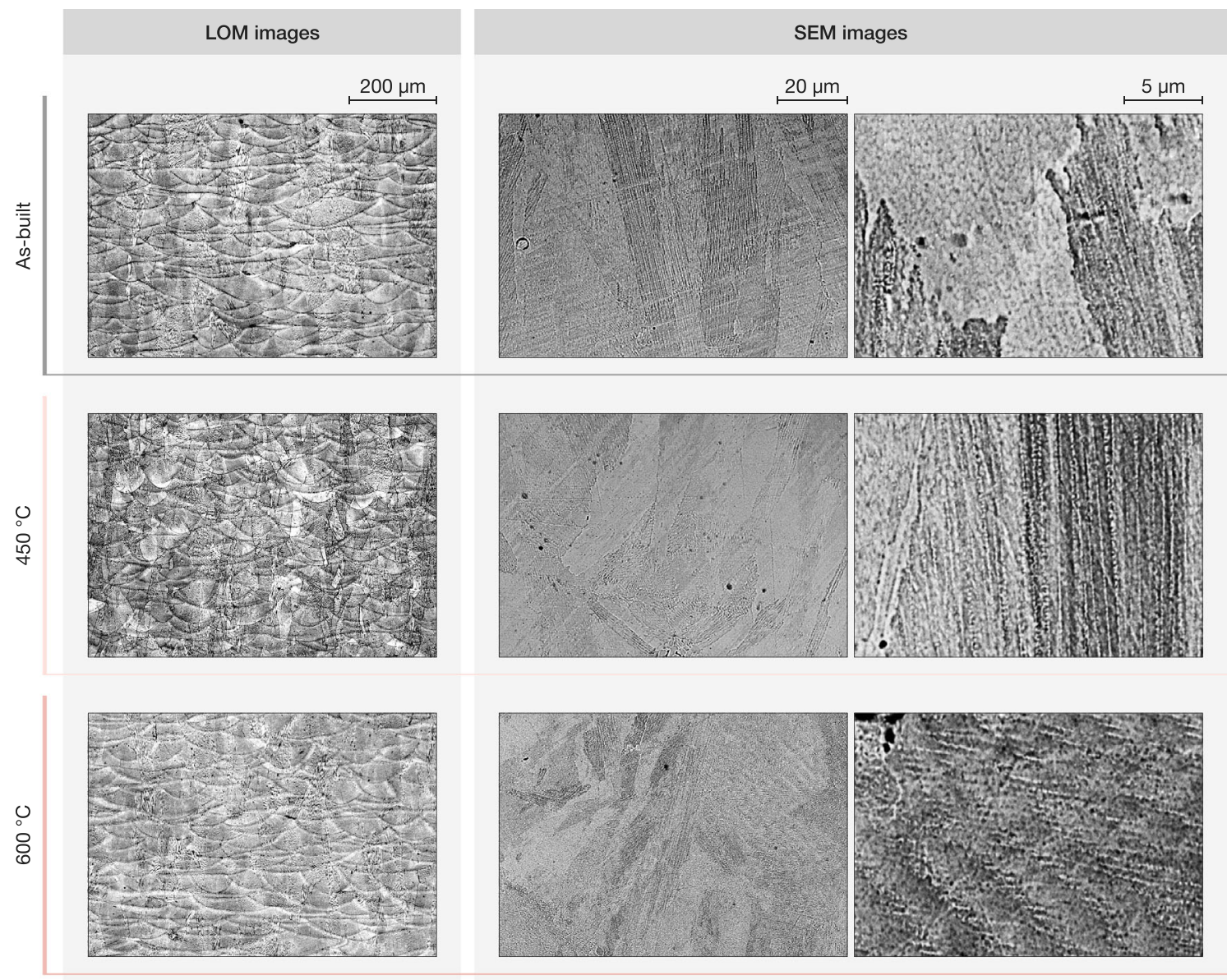

Fig. 2 LOM and SEM images of the L-PBF Inconel 718 samples in the as-built state and heat-treated at 450 and $600{ }^{\circ} \mathrm{C}$ for $1 \mathrm{~h}$. Kalling's No. 2 etchant was used 

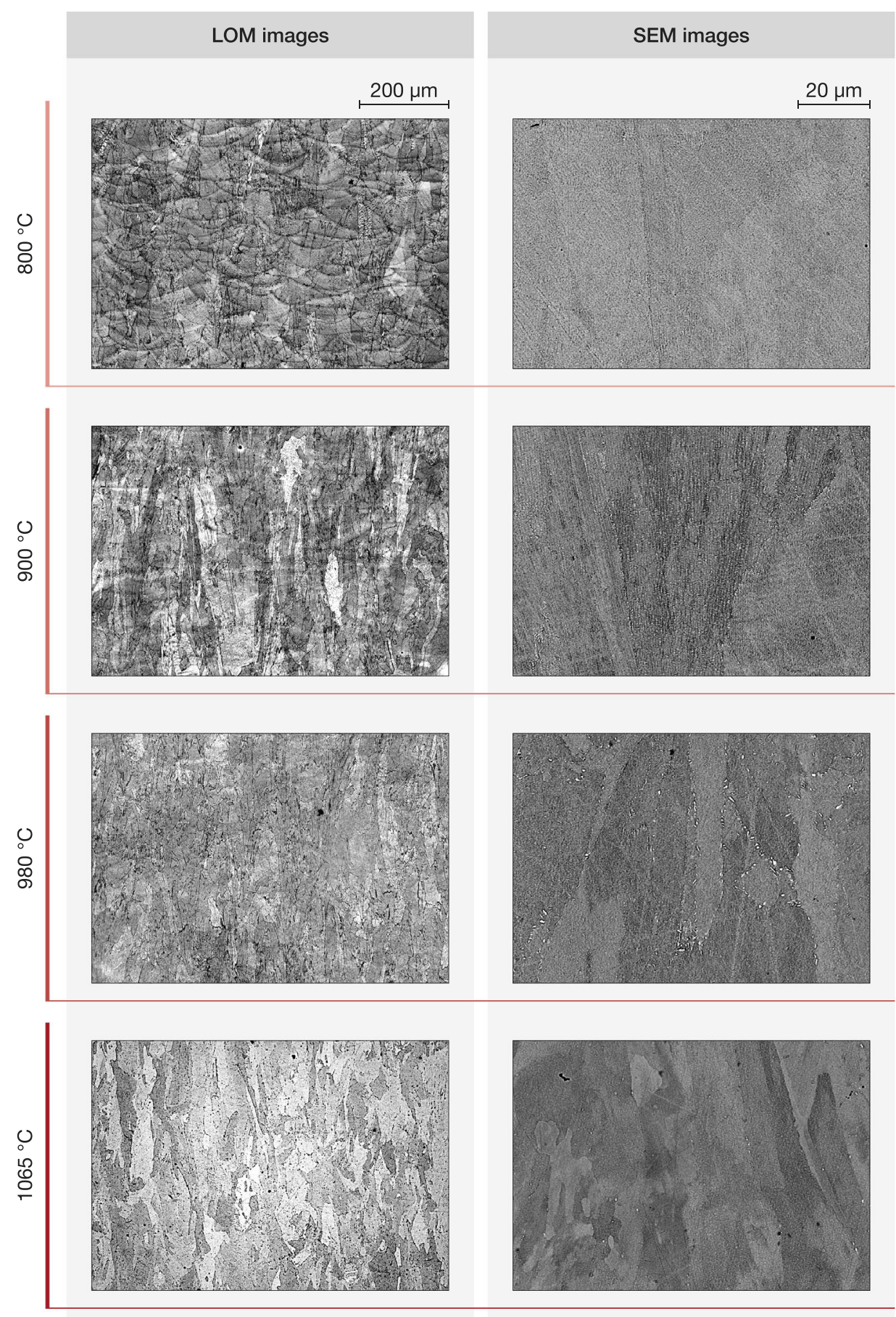

Fig. 3 LOM and SEM images of L-PBF IN 718 samples heat-treated at 800, 900, 980, and $1065{ }^{\circ} \mathrm{C}$ for 1 h. Kalling's No.2 was used

along the grain boundaries. These carbides tend to be formed along these areas that are enriched in segregated chemical elements ( $\mathrm{C}, \mathrm{Nb}$, etc.) (Ref 17, 21). Additionally, nanometric phases, such as $\gamma^{\prime \prime}$ phases, could form based on the TTT curves of the alloy (Ref34).

After heat treatments at 900 and $980{ }^{\circ} \mathrm{C}$, the microstructure revealed the formation of $\delta$ phases both along the grain boundaries and inside the grains. The $\delta$ phases of samples heat-treated at 900 and $980{ }^{\circ} \mathrm{C}$ exhibited enrichment in $\mathrm{Nb}$ and Ni (typical forming elements of this phase (Ref 12, 35). Inside the grains, the $\delta$ phases tended to form predominately along with the interdendritic areas enriched in $\mathrm{Nb}$. The samples heat-treated at $980{ }^{\circ} \mathrm{C}$ exhibited coarser $\delta$ phases than samples heat-treated $900{ }^{\circ} \mathrm{C}$. The samples heat-treated at $980{ }^{\circ} \mathrm{C}$ revealed the presence of $\delta$ phases from sub-micrometric to around $4 \mu \mathrm{m}$, while the samples heat-treated at $900{ }^{\circ} \mathrm{C}$ mainly exhibited maximum dimensions up to around $2 \mu \mathrm{m}$.

It should be noted that the distribution and dimension of $\delta$ phases must be carefully controlled. This phase tends to increase the hardness, but its elevated concentration and dimensions can be detrimental to the ductility of the material. Moreover, $\delta$ phases reduce $\mathrm{Nb}$ within austenitic matric, which is essential for $\gamma^{\prime \prime}$ phase formation during aging treatments 

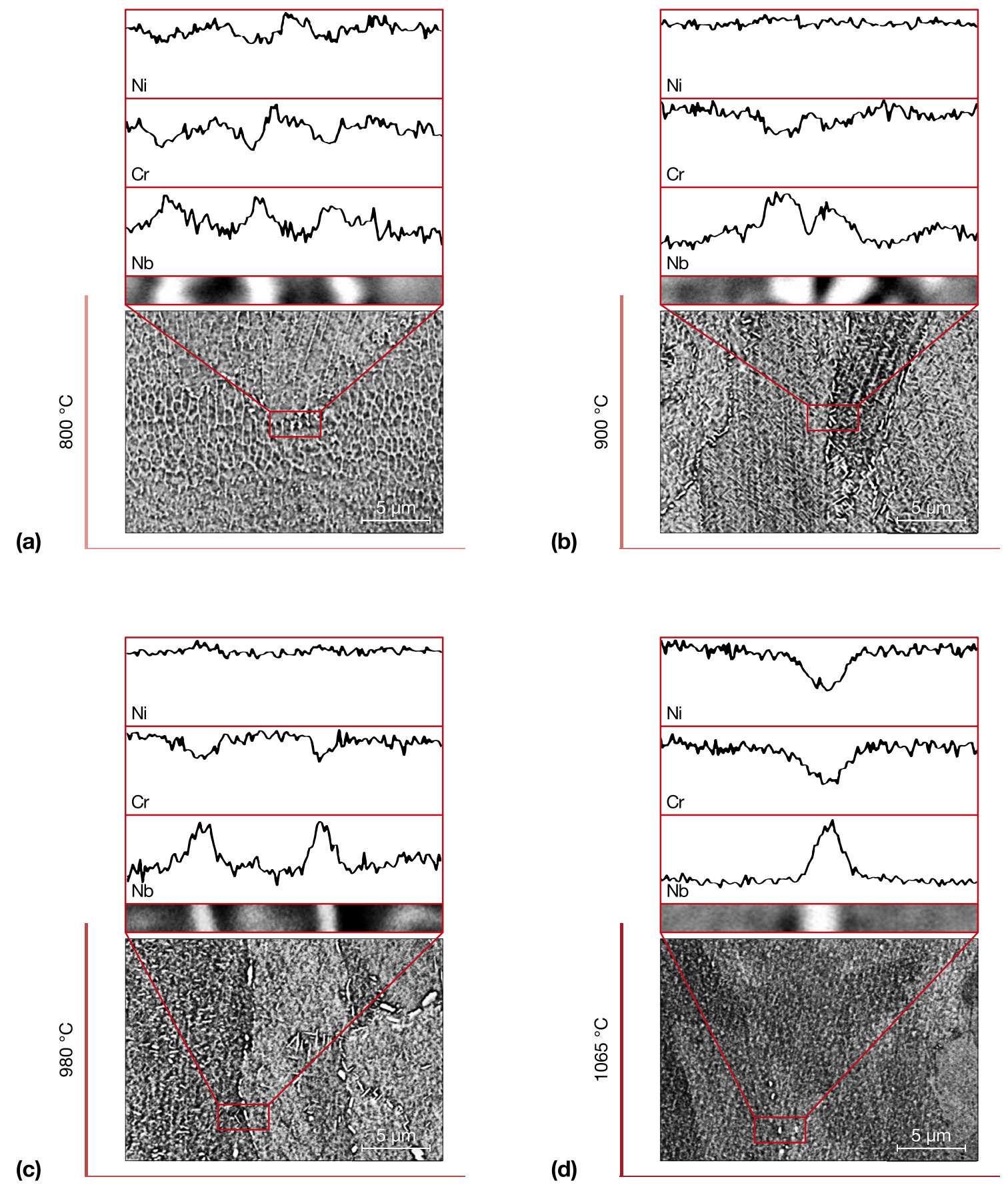

Fig. 4 SEM images and EDS scan lines of the heat-treated IN 718 samples (a) 800, (b) 900, (c) 980, and (d) $1065{ }^{\circ} \mathrm{C}$ for $1 \mathrm{~h}$. The EDS scan lines revealed the formation of carbides for samples heat-treated at 800 and $1065^{\circ} \mathrm{C}$ and the formation of $\delta$ phases for samples heat-treated at 900 and $980{ }^{\circ} \mathrm{C}$

(Ref 2). From the microstructure analyses, $900{ }^{\circ} \mathrm{C}$ appeared to reduce the formation of large $\delta$ phases.

A solution annealing at $1065{ }^{\circ} \mathrm{C}$ exhibited the complete dissolution of dendritic structures. The SEM images show the presence of intergranular carbides rich in $\mathrm{Nb}$ associated with the depletion of $\mathrm{Ni}$ and $\mathrm{Cr}$ with dimensions up to around $1 \mu \mathrm{m}$.

\subsection{XRD Analysis and Hardness Evolution}

The microstructure development under heat treatments can be discussed employing the hardness and lattice parameter of $\gamma$ phase. For Ni-based superalloys, it was reported that phase formation could involve both an increment of the hardness and a reduction of the lattice parameters of the $\gamma$ phase due to chemical elements depletion from the matrix. Differently, the dendritic dissolution can increase the lattice parameter of the $\gamma$ phase (Ref 17, 36, 37).

For the as-built and heat-treated samples, the hardness and the lattice parameter of $\gamma$ phase are displayed in Fig. 5(a) and (b), respectively.

The hardness and lattice parameter of $\gamma$ phase of heat-treated samples at 450 and $600{ }^{\circ} \mathrm{C}$ resulted to be similar to the as-built ones, indicating no detectable modifications. On the other hand, 

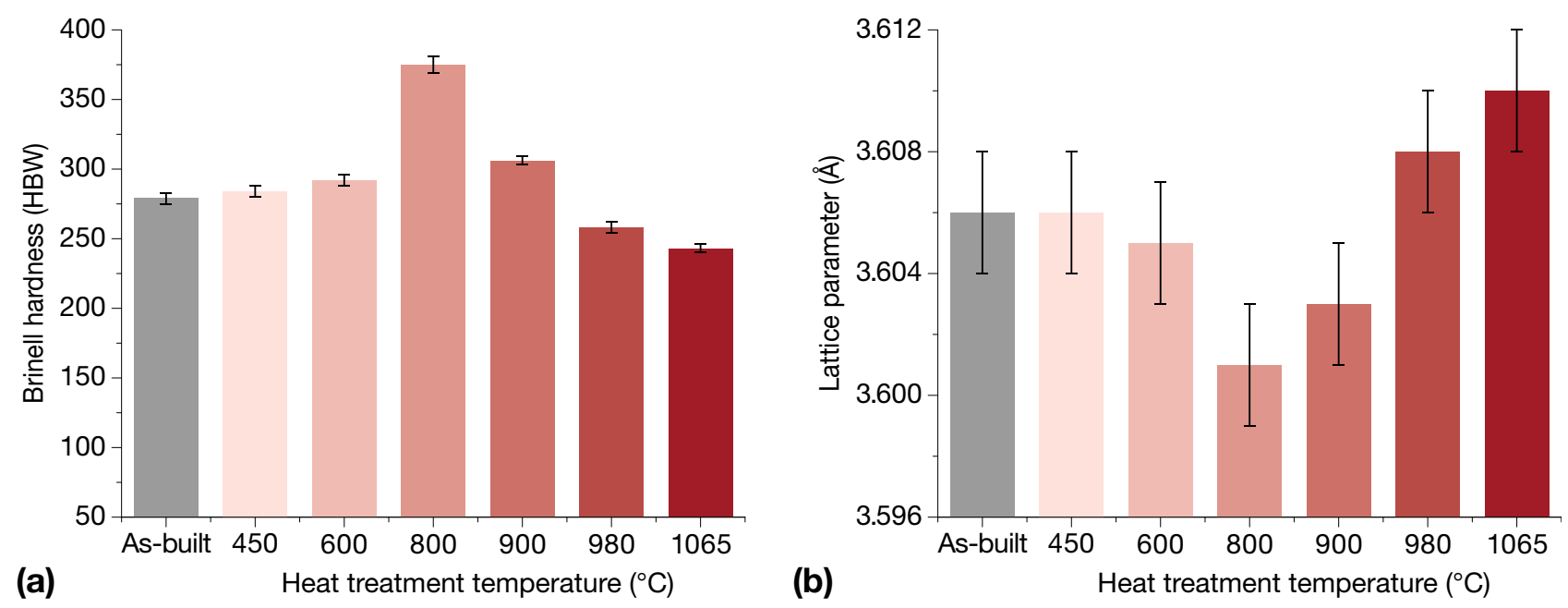

Fig. 5 (a) Hardness of as-built and heat-treated samples at 450, 600, 800, 900, 980, and $1065{ }^{\circ} \mathrm{C}$; (b) Lattice parameter of $\gamma$ phase for the asbuilt and heat-treated samples at $450,600,800,900,980$, and $1065^{\circ} \mathrm{C}$
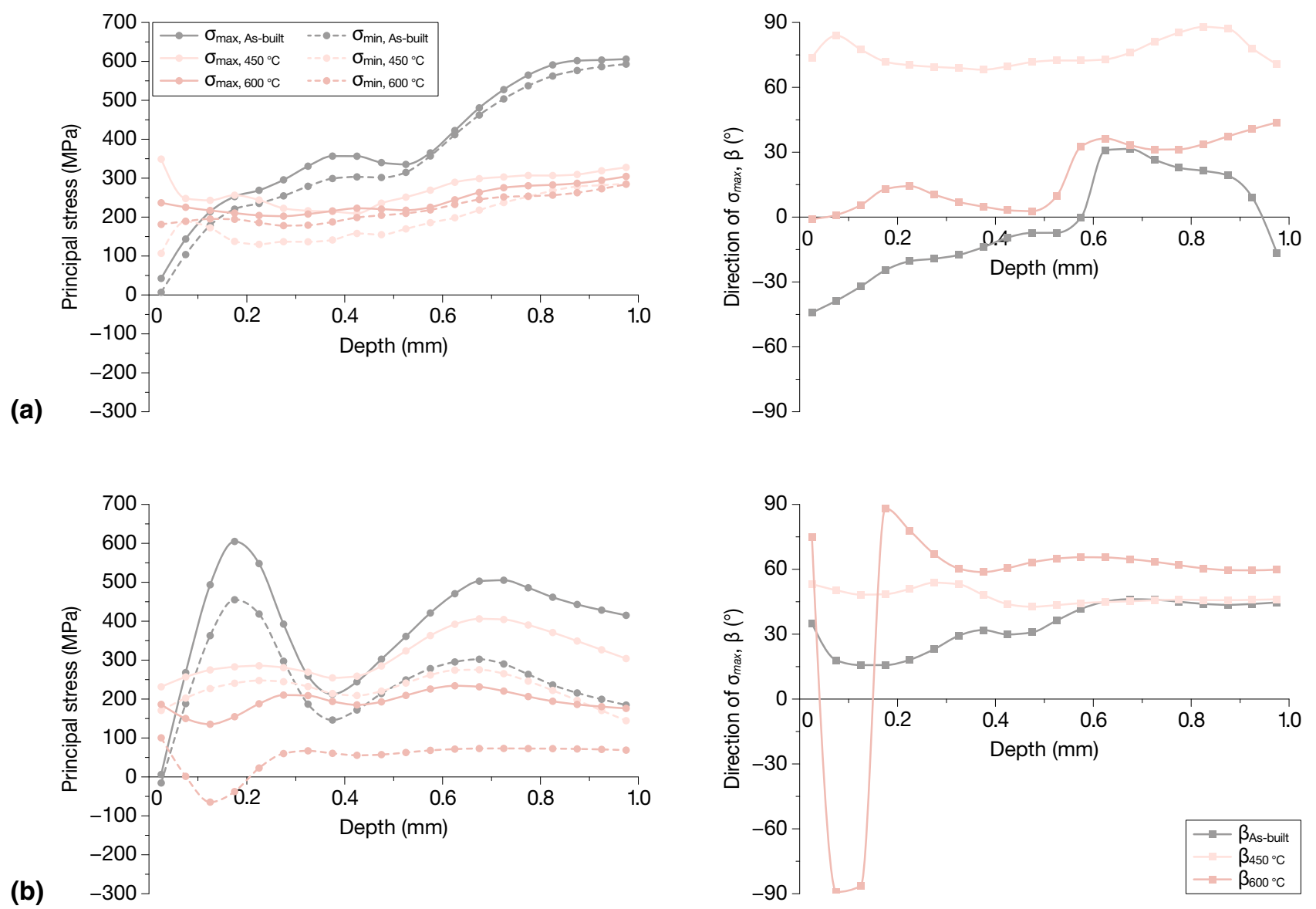

Fig. 6 Residual stress profiles (a) on the top surface and (b) on the lateral side of the L-PBF IN 718 samples in the as-built state and heattreated at 450 and $600{ }^{\circ} \mathrm{C}$ for $1 \mathrm{~h}$

heat treatment at $800{ }^{\circ} \mathrm{C}$ involved a significant hardness increment coupled to lattice parameter reduction with respect to the as-built state. This was caused by the formation of carbides and more probably nanometric $\gamma^{\prime \prime}$ phases, strengthening the material and reducing chemical elements from the matrix.
Samples heat-treated at $900{ }^{\circ} \mathrm{C}$ revealed higher hardness and slightly lower average lattice parameter than the as-built state. This can be attributed to the $\delta$ phase formation.

The standard solution annealing at $980{ }^{\circ} \mathrm{C}$ revealed lower hardness and greater lattice parameter with respect to the asbuilt state. Even though the material presents a consistent 

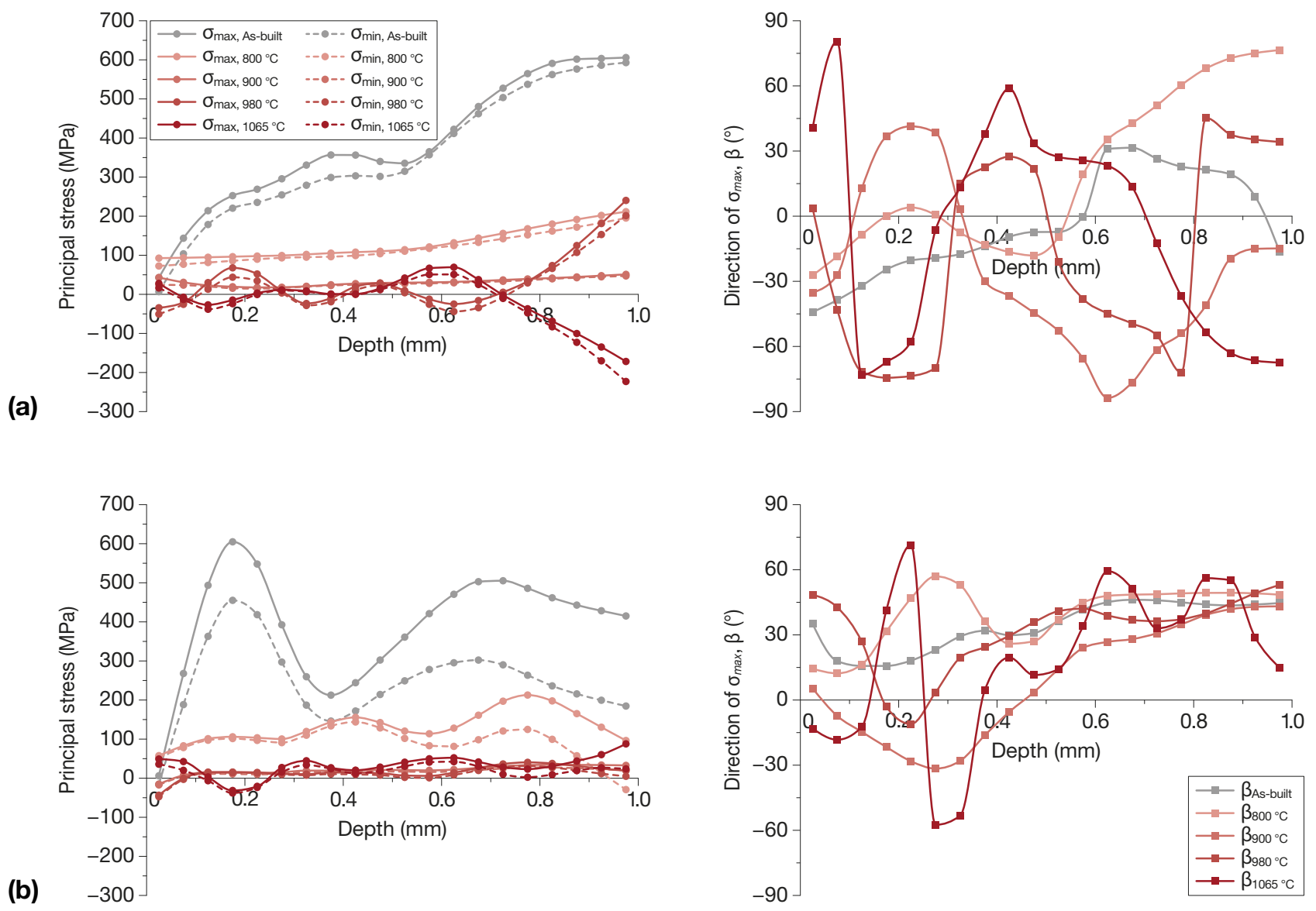

Fig. 7 Residual stress profiles (a) on the top surface and (b) on the lateral side of the L-PBF IN 718 samples in the as-built state and heattreated at $800,900,980$, and $1065^{\circ} \mathrm{C}$ for $1 \mathrm{~h}$

quantity of $\delta$ phases, the suppression of the melt pool structures and the partial dissolution of the dendritic structures lead to reduce the hardness and increase the lattice parameters.

The samples heat-treated at $1065{ }^{\circ} \mathrm{C}$ revealed the lowest hardness correlated with the highest lattice parameter. This derived from the complete suppression of melt pool structures and dendritic structures together with carbides formation occurred.

The hardness of the as-built and heat-treated samples at standard temperatures $\left(980\right.$ and $1065{ }^{\circ} \mathrm{C}$ ) are in good agreement with the literature using the hardness conversion of ASTM E140 (Ref 17).

\subsection{Residual Stresses}

The residual stresses for the as-built and different heattreated IN 718 conditions along the top and lateral sides are reported in Fig. 6 and 7.

The as-built state showed the highest residual stress values, that were generated by the L-PBF process. Stresses were positive in sign, and on the top side maximum and minimum stresses were very close, indicating a biaxial tensile state. The stress profile below the top surface showed an initial increase from null stress to $250 \mathrm{MPa}$ within the first $0.2 \mathrm{~mm}$, then a moderate increase up to $350 \mathrm{MPa}$ in the next $0.4 \mathrm{~mm}$ and finally a rapid rise to $600 \mathrm{MPa}$ (almost reaching the yield strength of the as-built material built along the z-axis (Ref 38) from a depth of $0.6 \mathrm{~mm}$. According to ASTM E837 -13a standard, the uncertainty in stress value determination by the hole drilling method is on average $\pm 10 \%$. Also, the direction of the principal stress showed an abrupt variation at a depth of $0.6 \mathrm{~mm}$. Differently, the stress on the lateral surface was highest near the surface, reaching the maximum value of $600 \mathrm{MPa}$ at $0.2 \mathrm{~mm}$ depth, and then oscillated between 200 and $500 \mathrm{MPa}$ at higher depth.

The effectiveness of heat treatments at 450 and $600{ }^{\circ} \mathrm{C}$ on the reduction of residual stresses is clearly visible in Fig. 6. As concerns the top surface, quite uniform biaxial stresses of about $200 \mathrm{MPa}$ were observed in both cases, with a moderate increase to $300 \mathrm{MPa}$ only at higher depth. The maximum stress was around $45 \%$ of the yield stress of the material in the as-built state built along the z-axis (Ref 38 ). Different effects of the two heat treatments were instead observed on the lateral surfaces, and the somewhat oscillating stress still remained higher than $200 \mathrm{MPa}$ after the heat treatment at $450{ }^{\circ} \mathrm{C}$, whereas it was below $200 \mathrm{MPa}$ when the higher temperature of $600{ }^{\circ} \mathrm{C}$ was adopted. This result suggests that the heat treatment at $600{ }^{\circ} \mathrm{C}$ is more effective in reducing the internal stresses.

A more remarkable residual stress reduction was obtained after the heat treatment at $800{ }^{\circ} \mathrm{C}$ (Fig. 7). After this treatment, the stress on the top side decreased to $100 \mathrm{MPa}$, with a slight increase to $200 \mathrm{MPa}$ at higher depth. On the lateral side, the stress oscillated between 100 and $200 \mathrm{MPa}$. 


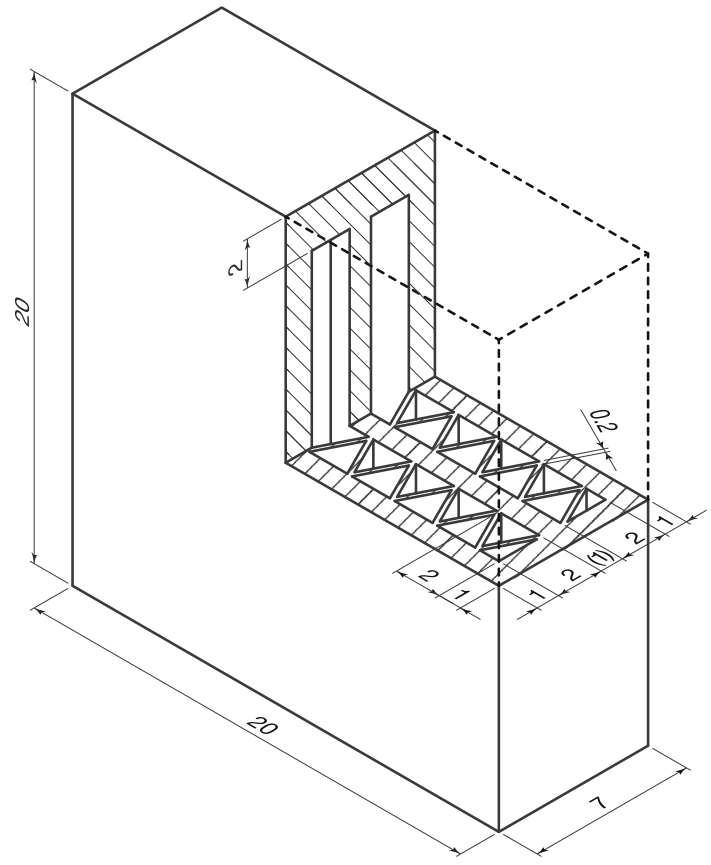

Fig. 8 Geometry of the component with narrow internal channels (all dimensions in $\mathrm{mm}$ )

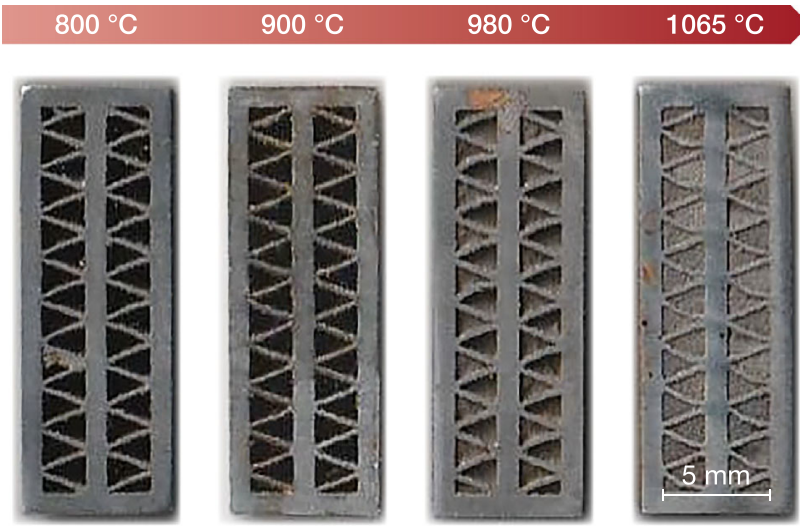

Fig. 9 Components after cutting with narrow internal channels underwent to different heat treatments

On the other hand, heat treatment at 900,980 , and $1065{ }^{\circ} \mathrm{C}$ revealed the almost complete elimination of residual stresses (in this case the $\beta$-angle indication is not significant). The oscillating trends that were measured after the 980 and $1065{ }^{\circ} \mathrm{C}$ heat treatments, and that appeared amplified at higher depth may be ascribed to the formation of precipitate areas in the microstructure.

\subsection{Components with Internal Channels}

The investigated heat treatments were applied to components with narrow internal channels made of IN 718 by L-PBF. The geometry of these components is detailed in Fig. 8. After performing the heat treatments, the components were cut and checked if the powder was sintered within the narrow channels.

For heat treatments up to $900{ }^{\circ} \mathrm{C}$ for $1 \mathrm{~h}$, the powder was not sintered within the internal channel. Differently, partial sintering of the powder occurred after heat treatments at 980 and $1065{ }^{\circ} \mathrm{C}$ for $1 \mathrm{~h}$, entrapping the powder within the internal channels, as displayed in Fig. 9.

It is, therefore, evident that standard heat treatments could not be performed without before removing the powder from the internal channels. On the other hand, considering the current results, heat treatments at 800 and $900{ }^{\circ} \mathrm{C}$ could be performed to reduce the internal stresses without involving the sintering of the powder within the internal channels.

\section{Conclusions}

The influence of different heat treatments on the microstructure and residual stresses of L-PBF IN 718 alloy was investigated. The residual stresses within the material can lead to components distortions, making it necessary to perform a post-heat treatment. The current work revealed that:

- heat treatments at 450 and $600{ }^{\circ} \mathrm{C}$ for $1 \mathrm{~h}$ slightly reduced the residual stresses within the material, without providing consistent microstructure alterations with respect to the asbuilt state;

- higher temperatures resulted to be more effective in reducing the residual stresses, involving a different degree of microstructure modifications based on the temperature;

- heat treatment at $800{ }^{\circ} \mathrm{C}$ for $1 \mathrm{~h}$ produced consistent mitigation of the residual stresses, generating very fine phases composed of intergranular carbides and most likely nanometric $\gamma^{\prime \prime}$ phases, drastically increasing the hardness of the samples;

- heat treatment at $900{ }^{\circ} \mathrm{C}$ for $1 \mathrm{~h}$ resulted to be effective in the suppression of residual stresses revealing the formation of $\delta$ phases correlated with a slight increment of hardness compared to the as-built state;

- the standard solution-annealing temperatures at 980 and $1065{ }^{\circ} \mathrm{C}$ for $1 \mathrm{~h}$ eliminated the residual stresses but, at the same time, promoted significant dendritic dissolution correlated with hardness decrement. In particular, the samples heat-treated at $980{ }^{\circ} \mathrm{C}$ showed bigger $\delta$ phases than samples heat-treated at $900{ }^{\circ} \mathrm{C}$. The samples heat-treated at $1065^{\circ} \mathrm{C}$ revealed the presence of intergranular carbides associated with a complete dissolution of dendritic structures.

Therefore, heat treatments performed at low temperatures with respect to the standard temperatures could be considered as tailored stress-relieving treatments for the L-PBF material, and consequently, decreasing distortions of the components generating a limited impact on the microstructure.

These heat treatments were also performed on components with narrow internal channels. For the standard heat treatments at 980 and $1065^{\circ} \mathrm{C}$, the powder was partially sintered within the channels. Differently, heat treatments at 800 and $900{ }^{\circ} \mathrm{C}$ could mitigate the residual stresses without triggering the initial sintering of the powder within the internal channels, which can be easily eliminated after removing the specimens from the building platform.

\section{Acknowledgments}

The authors would like to acknowledge the European Horizon 2020 research and innovation programme; grant agreement 
No.723795/4D Hybrid-Novel ALL-IN-ONE machines, robots, and systems for affordable, worldwide and lifetime distributed 3D hybrid manufacturing and repair operations. This work has been partially supported by "Ministero dell'Istruzione, dell'Università e della Ricerca" Award "TESHUN-83486178370409 finanziamento dipartimenti di eccellenza CAP. 1694 TIT. 232 ART. 6”. Moreover, the authors would like to acknowledge the Integrated Additive Manufacturing Centre at Politecnico di Torino (IAM@PoliTo) where the specimens were fabricated and characterized. Finally, the authors would like to thank Mr. Roberto Manzo for support in the preparation of samples during this research.

\section{Funding}

Open access funding provided by Politecnico di Torino within the CRUI-CARE Agreement.

\section{Open Access}

This article is licensed under a Creative Commons Attribution 4.0 International License, which permits use, sharing, adaptation, distribution and reproduction in any medium or format, as long as you give appropriate credit to the original author(s) and the source, provide a link to the Creative Commons licence, and indicate if changes were made. The images or other third party material in this article are included in the article's Creative Commons licence, unless indicated otherwise in a credit line to the material. If material is not included in the article's Creative Commons licence and your intended use is not permitted by statutory regulation or exceeds the permitted use, you will need to obtain permission directly from the copyright holder. To view a copy of this licence, visit http://creativecommons.org/licenses/by/4.0/.

\section{References}

1. S.A. Nalawade, M. Sundararaman, J.B. Singh, A. Verma, and R. Kishore, Precipitation of $\gamma^{\prime}$ Phase in $\delta$-Precipitated Alloy 718 during Deformation at Elevated Temperatures, Mater. Sci. Eng., A, 2010, 527(12), p 2906-2909. https://doi.org/10.1016/j.msea.2010.01. 006

2. H. Zhang, C. Li, Q. Guo, Z. Ma, Y. Huang, H. Li, and Y. Liu, Hot Tensile Behavior of Cold-Rolled Inconel 718 Alloy at $650 \mathrm{C}$ : the Role of $\delta$ Phase, Mater. Sci. Eng., A, 2018, 722, p 136-146. https://doi.org/ 10.1016/j.msea.2018.02.093

3. A. Chamanfar, L. Sarrat, M. Jahazi, M. Asadi, A. Weck, and A.K. Koul, Microstructural Characteristics of Forged and Heat Treated Inconel-718 Disks, Mater. Des., 2013, 52, p 791-800. https://doi.org/ 10.1016/j.matdes.2013.06.004

4. L. Chang, W. Sun, Y. Cui, F. Zhang, and R. Yang, Effect of Heat Treatment on Microstructure and Mechanical Properties of the HotIsostatic-Pressed Inconel 718 Powder Compact, J. Alloys Compd., 2014, 590, p 227-232. https://doi.org/10.1016/j.jallcom.2013.12.107

5. H. Qi, M. Azer, and A. Ritter, Studies of Standard Heat Treatment Effects on Microstructure and Mechanical Properties of Laser Net Shape Manufactured INCONEL 718, Metall. Mater. Trans. A Phys. Metall. Mater. Sci, 2009, 40(10), p 2410-2422. https://doi.org/10.1007/ s11661-009-9949-3

6. C.M. Kuo, Y.T. Yang, H.Y. Bor, C.N. Wei, and C.C. Tai, Aging Effects on the Microstructure and Creep Behavior of Inconel 718 Superalloy, Mater. Sci. Eng., A, 2009, 510-511, p 289-294. https://doi.org/10.10 16/j.msea.2008.04.097

7. C. Zhong, A. Gasser, J. Kittel, K. Wissenbach, and R. Poprawe, Improvement of Material Performance of Inconel 718 Formed by High Deposition-Rate Laser Metal Deposition, Mater. Des., 2016, 98, p 128 134. https://doi.org/10.1016/j.matdes.2016.03.006
8. D. Herzog, V. Seyda, E. Wycisk, and C. Emmelmann, Additive Manufacturing of Metals, Acta Mater., 2016, 117, p 371-392. https://d oi.org/10.1016/j.actamat.2016.07.019

9. C.Y. Yap, C.K. Chua, Z.L. Dong, Z.H. Liu, D.Q. Zhang, L.E. Loh, and S.L. Sing, Review of Selective Laser Melting: materials and Applications, Appl. Phys. Rev., 2015, 2(4), p 1-22. https://doi.org/10.1063/1. 4935926

10. W.E. King, A.T. Anderson, R.M. Ferencz, N.E. Hodge, C. Kamath, S.A. Khairallah, and A.M. Rubenchik, Laser Powder Bed Fusion Additive Manufacturing of Metals; Physics, Computational, and Materials Challenges, Appl. Phys. Rev., 2015, 2(4), p 041304. https:// doi.org/10.1063/1.4937809

11. G. Marchese, E. Bassini, M. Calandri, E.P. Ambrosio, F. Calignano, M. Lorusso, D. Manfredi, M. Pavese, S. Biamino, and P. Fino, Microstructural Investigation of As-Fabricated and Heat-Treated Inconel 625 and Inconel 718 Fabricated by Direct Metal Laser Sintering: contribution of Politecnico Di Torino and Istituto Italiano Di Tecnologia (IIT) Di Torino, Met. Powder Rep., 2016, 71(4), p 273-278. https://doi.org/10.1016/j.mprp.2016.06.002

12. K. Moussaoui, W. Rubio, M. Mousseigne, T. Sultan, and F. Rezai, Effects of Selective Laser Melting Additive Manufacturing Parameters of Inconel 718 on Porosity, Microstructure and Mechanical Properties, Mater. Sci. Eng. A, 2018, 735, p 182-190. https://doi.org/10.1016/j. msea.2018.08.037

13. Q. Jia and D. Gu, Selective Laser Melting Additive Manufacturing of Inconel 718 Superalloy Parts: densification, Microstructure and Properties, J. Alloys Compd., 2014, 585, p 713-721. https://doi.org/ 10.1016/j.jallcom.2013.09.171

14. L.N. Carter, X. Wang, N. Read, R. Khan, M. Aristizabal, K. Essa, and M.M. Attallah, Process Optimisation of Selective Laser Melting Using Energy Density Model for Nickel Based Superalloys, Mater. Sci. Technol., 2016, 32(7), p 657-661. https://doi.org/10.1179/174328471 5Y.0000000108

15. M. Calandri, D. Manfredi, F. Calignano, E.P. Ambrosio, S. Biamino, R. Lupoi, and D. Ugues, Solution Treatment Study of Inconel 718 Produced by SLM Additive Technique in View of the Oxidation Resistance, Adv. Eng. Mater., 2018, 20(11), p 1800351. https://doi.org/ 10.1002/adem.201800351

16. Z. Wang, K. Guan, M. Gao, X. Li, X. Chen, and X. Zeng, The Microstructure and Mechanical Properties of Deposited-IN718 by Selective Laser Melting, J. Alloys Compd., 2012, 513, p 518-523. h ttps://doi.org/10.1016/j.jallcom.2011.10.107

17. L. Zhou, A. Mehta, B. McWilliams, K. Cho, and Y. Sohn, Microstructure, Precipitates and Mechanical Properties of Powder Bed Fused Inconel 718 before and after Heat Treatment, J. Mater. Sci. Technol., 2019, 35(6), p 1153-1164. https://doi.org/10.1016/j.jmst.2018.12.006

18. J.L. Bartlett and X. Li, An Overview of Residual Stresses in Metal Powder Bed Fusion, Addit. Manuf, 2019, 27, p 131-149. https://doi. org/10.1016/j.addma.2019.02.020

19. M. Calandri, S. Yin, B. Aldwell, F. Calignano, R. Lupoi, and D. Ugues, Texture and Microstructural Features at Different Length Scales in Inconel 718 Produced by Selective Laser Melting, Materials (Basel), 2019, 12(8), p 1293. https://doi.org/10.3390/ma12081293

20. X. Wang and K. Chou, Effects of Thermal Cycles on the Microstructure Evolution of Inconel 718 during Selective Laser Melting Process, Addit. Manuf., 2017, 18, p 1-14. https://doi.org/10.1016/j.addma.2017. 08.016

21. W.M. Tucho, P. Cuvillier, A. Sjolyst-Kverneland, and V. Hansen, Microstructure and Hardness Studies of Inconel 718 Manufactured by Selective Laser Melting before and after Solution Heat Treatment, Mater. Sci. Eng., A, 2016, 2017(689), p 220-232. https://doi.org/10. 1016/j.msea.2017.02.062

22. D. Zhang, Z. Feng, C. Wang, W. Wang, Z. Liu, and W. Niu, Comparison of Microstructures and Mechanical Properties of Inconel 718 Alloy Processed by Selective Laser Melting and Casting, Mater. Sci. Eng., A, 2018, 724(100), p 357-367. https://doi.org/10.1016/j.ms ea.2018.03.073

23. G.H. Cao, T.Y. Sun, C.H. Wang, X. Li, M. Liu, Z.X. Zhang, P.F. Hu, A.M. Russell, R. Schneider, D. Gerthsen, Z.J. Zhou, C.P. Li, and G.F. Chen, Investigations of $\gamma^{\prime}, \gamma^{\prime \prime}$ and $\delta$ precipitates in heat-treated Inconel 718 alloy fabricated by selective laser melting, Mater. Charact., 2018, 136, p 398-406. https://doi.org/10.1016/j.matchar.2018.01.006

24. E. Chlebus, K. Gruber, B. Kuźnicka, J. Kurzac, and T. Kurzynowski, Effect of Heat Treatment on the Microstructure and Mechanical Properties of Inconel 718 Processed by Selective Laser Melting, Mater. 
Sci. Eng., A, 2015, 639, p 647-655. https://doi.org/10.1016/j.msea. 2015.05.035

25. A. Salmi and E. Atzeni, Residual Stress Analysis of Thin AlSi10Mg Parts Produced by Laser Powder Bed Fusion, Virtual Phys. Prototyp., 2020, 15(1), p 49-61. https://doi.org/10.1080/17452759.2019.1650237

26. A. Salmi and E. Atzeni, History of Residual Stresses during the Production Phases of AlSi10Mg Parts Processed by Powder Bed Additive Manufacturing Technology, Virtual Phys. Prototyp., 2017, 12(2), p 153-160. https://doi.org/10.1080/17452759.2017.1310439

27. N.C. Levkulich, S.L. Semiatin, J.E. Gockel, J.R. Middendorf, A.T. DeWald, and N.W. Klingbeil, The Effect of Process Parameters on Residual Stress Evolution and Distortion in the Laser Powder Bed Fusion of Ti-6Al-4 V, Addit. Manuf., 2019, 28, p 475-484. https://doi. org/10.1016/j.addma.2019.05.015

28. J.H. Yi, J.W. Kang, T.J. Wang, X. Wang, Y.Y. Hu, T. Feng, Y.L. Feng, and P.Y. Wu, Effect of Laser Energy Density on the Microstructure, Mechanical Properties, and Deformation of Inconel 718 Samples Fabricated by Selective Laser Melting, J. Alloys Compd., 2019, 786, p 481-488. https://doi.org/10.1016/j.jallcom.2019.01.377

29. Y. Lu, S. Wu, Y. Gan, T. Huang, C. Yang, L. Junjie, and J. Lin, Study on the Microstructure, Mechanical Property and Residual Stress of SLM Inconel-718 Alloy Manufactured by Differing Island Scanning Strategy, Opt. Laser Technol., 2015, 75, p 197-206. https://doi.org/10. 1016/j.optlastec.2015.07.009

30. D. Deng, R.L. Peng, H. Brodin, and J. Moverare, Microstructure and Mechanical Properties of Inconel 718 Produced by Selective Laser Melting: sample Orientation Dependence and Effects of Post Heat Treatments, Mater. Sci. Eng., A, 2018, 713, p 294-306. https://doi.org/ 10.1016/j.msea.2017.12.043

31. N. Nadammal, S. Cabeza, T. Mishurova, T. Thiede, A. Kromm, C. Seyfert, L. Farahbod, C. Haberland, J.A. Schneider, P.D. Portella, and G. Bruno, Effect of Hatch Length on the Development of Microstructure, Texture and Residual Stresses in Selective Laser Melted
Superalloy Inconel 718, Mater. Des., 2017, 134, p 139-150. https://d oi.org/10.1016/j.matdes.2017.08.049

32. R. Barros, F.J.G. Silva, R.M. Gouveia, A. Saboori, G. Marchese, S. Biamino, A. Salmi, and E. Atzeni, Laser Powder Bed Fusion of Inconel 718: residual Stress Analysis Before and After Heat Treatment, Metals (Basel), 2019, 9, p 1290. https://doi.org/10.3390/met9121290

33. B. Ahmad, S.O. van der Veen, M.E. Fitzpatrick, and H. Guo, Residual Stress Evaluation in Selective-Laser-Melting Additively Manufactured Titanium (Ti-6Al-4V) and Inconel 718 Using the Contour Method and Numerical Simulation, Addit. Manuf., 2018, 22, p 571-582. https://doi. org/10.1016/j.addma.2018.06.002

34. H. Chandler, Ed., Heat Treater's Guide: Practices and Procedures for Nonferrous Alloys, Materials Park, ASM International, 1996

35. M.J. Donachie and S.J. Donachie, Superalloys: A Technical Guide, 2nd ed., Materials Park, ASM International, 2002

36. G. Marchese, S. Parizia, M. Rashidi, A. Saboori, D. Manfredi, D. Ugues, M. Lombardi, E. Hryha, and S. Biamino, The Role of Texturing and Microstructure Evolution on the Tensile Behavior of Heat-Treated Inconel 625 Produced via Laser Powder Bed Fusion, Mater. Sci. Eng., A, 2020, 769, p 138500. https://doi.org/10.1016/j.msea.2019.13 8500

37. S. Li, Q. Wei, Y. Shi, Z. Zhu, and D. Zhang, Microstructure Characteristics of Inconel 625 Superalloy Manufactured by Selective Laser Melting, J. Mater. Sci. Technol., 2015, 31(9), p 946-952. http s://doi.org/10.1016/j.jmst.2014.09.020

38. EOS NickelAlloy IN718 (Datasheet). Available Online: 2020. https:// www.eos.info/en/additive-manufacturing/3d-printing-metal/dmls-metal -materials/nickel-alloys. Accessed 20 May 2020

Publisher's Note Springer Nature remains neutral with regard to jurisdictional claims in published maps and institutional affiliations. 